\title{
Note sur la translitération
}

Tous les termes vernaculaires sont translitérés selon les règles données pour les langues indiennes dans le Bulletin 64 de février 1964, édité par The Library of Congress, Processing Department, Cataloging Service (Washington). Une modification a été introduite pour le tamoul $: \underline{l}, \underline{r}, \underline{n}$, sont translitérés ici par $L, R, N$. Pour éviter toute confusion, il a été décidé de ne jamais commencer un terme translitéré par unemajuscule, même s'il s'agit d'un nom propre.

Les termes sanskrits sont suivis de l'indication (skr.), les termes tamouls de l'indication (tam.) dans les seuls cas où il était nécessaire de préciser. Lorsqu'un terme tamoul est directement dérivé du sanskrit, il a souvent été jugé préférable d'en donne r la forme sanskrite: par exemple, gräma "village" (skr.), au lieu de kirāmam (tam.); dharma "loi, ordre"(skr.), au lieu de tarumam (tam.).

Ne sont pas translitérés les noms de lieu, de villes, de rivières, certains termes administratifs comme pancayat, taluk... Les noms de divinités sont donnés sous une forme courante, après avoir été une première fois translitérés.

Sur la prononciation, il n'est donné ici qu'un minimum d'indications :

- En tamoul, les consonnes $k, t, t, p$ sont sonores et plus ou moins équivalentes à $g, d, b$. Lorsqu'elles sont redoublées ou à l'initiale, elles sont sourdes.

- En tamoul et en sanskrit, u (bref ou long) se prononce "ou".

N. B. Dans un mot tamoul, c se prononce comme la sifflante $s$ (ou ç); redoublミ, il se lit "ts" ou "tch". En outre, c sert à translitérer toutes les iifflantes et les palatales des termes empruntés au sanskrit. Mais dans un mot sanskrit, c est une palatale: "ch". 


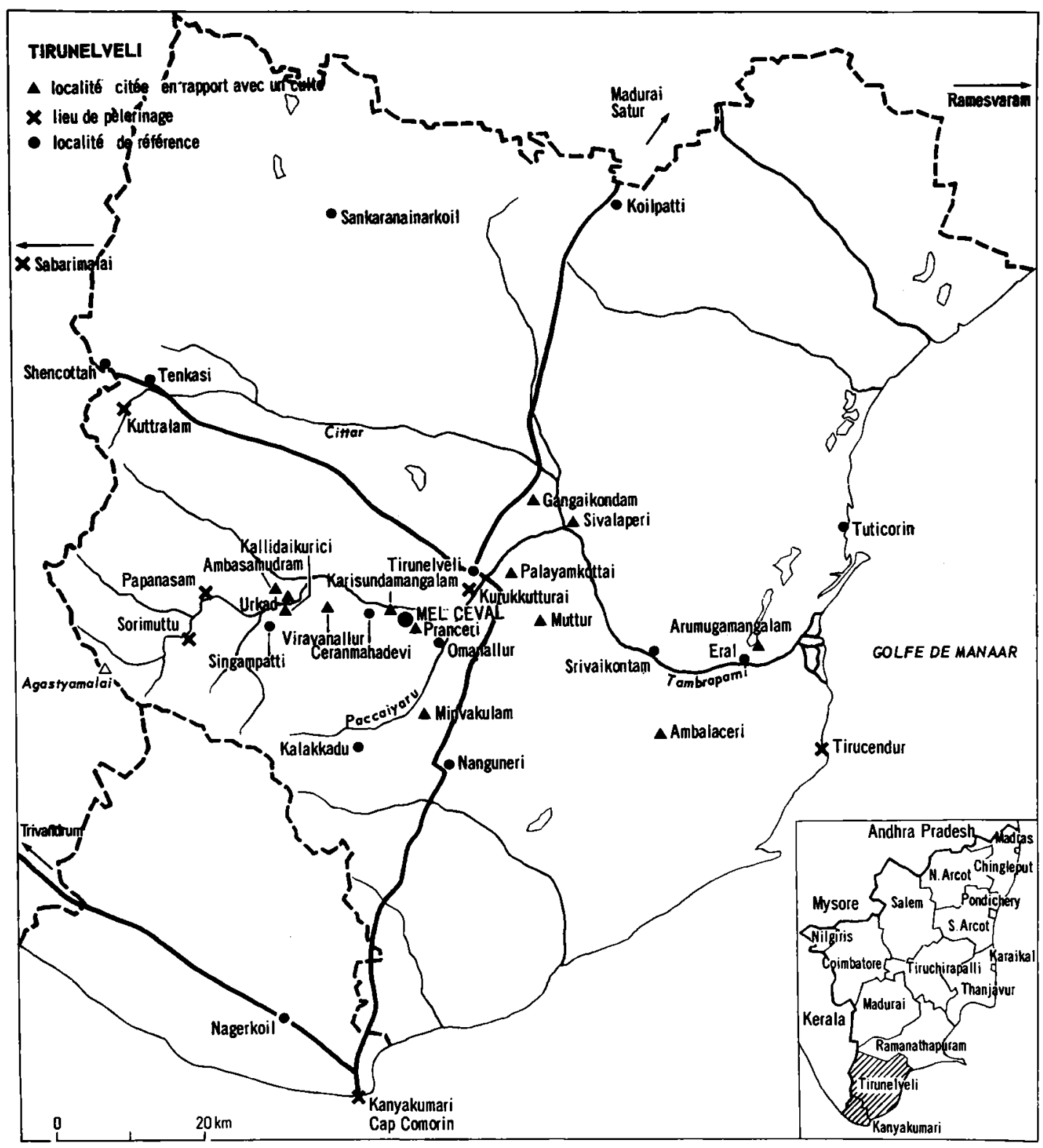

